\title{
FORMULATION, CHARACTERIZATION, STABILITY, INVITRO EVALUATION AND OPTIMIZATION OF DIACEREIN NIOSOMES
}

\author{
Abdelsaboor A. Hassan, Ahmed Lila, Fathy Ibrahim Abd Allah, Khalid Mohammed El Say \\ and Alaa Eldin Ali Kassem.
}

Pharmaceutics and Industrial Pharmacy Dept., Faculty of Pharmacy (Boys), Al-Azhar

University.

\begin{abstract}
Niosomes or non-ionic surfactants vesicles are microscopic lamellar structures formed on the admixture of a non-ionic surfactant, cholesterol and stearylamine with subsequent hydration in aqueous media. The delivery of drugs by "vesicular drug delivery system" such as niosomes provides several important advantages over conventional drug therapy. Diacerein is an Interleukin-1 inhibitor and it is highly effective in relieving the symptoms of osteoarthritis. Diacerein, in contrast to NSAIDs, are potent inhibitor of IL-1 beta induced nitric oxide production by chondrocytes and cartilage, without reducing prostaglandin E2 production.

The main objective of this study was to design suitable niosome-encapsulated drug delivery for anti-inflammatory drugs like Diacerein and evaluate the vesicle size, entrapment efficiency, in vitro release and physical stability of the system. Non-ionic surfactants used were Tween (40\&60), cholesterol and stearylamine in molar ratio 1:1:0.1. The niosomes were prepared by thin film hydration method. The higher entrapment efficiency was observed with niosome (F11) prepared from tween 60, cholesterol and $2.5 \mathrm{~min}$ sonication. The release pattern shown by these formulations were first order \& Higuchi diffusion controlled mechanism. The physical stability study show that niosomal preparation stored at refrigerated temperature for 60 days show maximum drug retained compare to room temperature and elevated temperature conditions. Finding of all this investigation conclusively demonstrate prolongation of drug release at a constant and controlled rate after niosomal encapsulation of Diacerein.
\end{abstract}

Keywords: Formulation, Stability, Niosome, Cholesterol, Diacerein, Tween, Stearylamine

\section{INTRODUCTION}

The basic goal of drug therapy is to achieve a steady state blood or tissue level that is therapeutically effective and nontoxic for an extended period. The design of proper dosage regimen is an important element in accomplishing this goal (Satturwar et al., 2002). Novel drug delivery systems aim to deliver the drug at a rate directed by the needs of the body during the period of treatment and channel the active entity to the site of action (Biju $\boldsymbol{e t}$ al., 2006). Targeted drug delivery implies for selective and effective localization of pharmacologically active moiety at preidentified (preselected) targeted (s) in therapeutic concentration while restricting its access to nontarget normal cellular linings thus minimizing toxic effects and maximizing therapeutic index. Targeted drug delivery is an event where a drug carrier complex/conjugate delivers drug (s) exclusively to the preselected targeted cells in a specific manner (Vyas and Khar, 2004). To pursue optical drug action, functional molecules could be transported by a carrier to the site of action and released to perform their task (Shahiwala and Misra, 2002).

The targeting methods may be classified as chemical methods, co-valent bonding and physical methods. Chemical methods involve chemical modification of the parent compound to a derivative, which is activated only at the target site. Various physical methods make use 
of the carriers such as liposomes, niosomes, resealed erythrocytes, nano-particles, platelets, magnetic microspheres, and monoclonal antibodies. Recently niosomal drug delivery system (A particulate colloidal carrier system) is drawing attention due to its significant advantages over conventional drug delivery system. It is reported that niosomes are non-ionic surfactant vesicles inclosing an aqueous phase and a wide range of molecules could be encapsulated within aqueous spaces of lipid membrane vesicles. Niosomes or non-ionic surfactants vesicles are microscopic lamellar structures formed on the admixture of a non-ionic surfactant, cholesterol and stearylamine with subsequent hydration in aqueous media (Sheena $\boldsymbol{e t}$ al., 1998). Diacerein directly inhibits IL-1 synthesis, release, down modulate IL-1 induced activities and have been shown to posses disease modifying effect in experimental models of osteoarthritis and in human subjects with finger joint and knee osteoarthritis, (Fidelix et al., 2006)

The present study was aimed for formulating niosomes of diacerein (IL-1 inhibitor), optimizing the formulation, characterizing them and assessing in vitro performance of the system.

\section{MATERIALS AND METHODS}

\section{Materials and Equibement}

Diacerein (NUTRA Specialities Private Limited) was obtained as a gift sample from ADCO, Egypt. Tweens (40 and 60) were procured from El-Nasr Pharmaceutical Chemicals Co (ADWIC), Cairo, Egypt. Cholesterol was procured MERCK, E.Merck, and Darmstadt. Stearylamine: purchased from Fluka, Sigma-Aldrich chemie Riedstr.2, Germany. Solvents and other reagents were of analytical grade. All the Ingredients were used without further purification. Phosphate Buffer saline (PBS) pH 7.4 was prepared as described in the Indian Pharmacopia1996. Statistical package STATGRAPHICS plus (version 4, Manugistics Inc., Rockville, MD, USA). Rotary evaporator:(Bibby Sterilin LTD, Stone StaffordshireEngland).UV spectrophotometer(Shimadzu UV-1650 P.C.Japan). Bio centrifuge (BiofugePrimo, Heraeus). Mastersizer(X ver.2.15, Malvern instruments Ltd.Malvern, UK). Rotary shaker Bath(Stuart SBS30, Bibby Sterilin LTD, Stone Staffordshire- England). Dissolution test system (Hanson research - Hanson virtual instruments, SR8 plus USA). Probe Sonicator(Cole-Parmer Instrument Co., Chicago-Illinois).

\section{Methods}

\section{Preparation of Diacerein Niosomes}

Niosomes were prepared by using thin film hydration method. Drug, nonionic surfactants and cholesterol were taken in molar ratio 1:1. Different niosomal formulations were prepared by thin film hydration technique reported by Azmin et al, (1985). Accurately weighed quantities of surfactant (either tween 40 or 60) and cholesterol, were dissolved in $10 \mathrm{ml}$ of chloroform in a round bottom flask (Abdulhasan et al., 2010). The solvent mixture was evaporated in a rotary evaporator under reduced pressure at a temperature of $60 \pm 5{ }^{0} \mathrm{C}$ and the flask rotated until a smooth, dry film was obtained. The film was hydrated with $25 \mathrm{ml}$ of PBS 7.4 containing Diacerein $(0.5 \%)$ at $60{ }^{\circ} \mathrm{C}$ with gentle shaking on a water bath. The niosomal suspension was then transferred to a suitable glass container and sonicated using probe sonicator in an ice bath for heat dissipation. The sonicated dispersion was then allowed to stand for about 2 hours at room temperature to form niosomes. The formulation was stored in refrigerator (Sakthivel et al., 2012). 
A technique of Box-Behnken design (Box and Behnken, 1960) taking three prime selected formulation variables (factors) at three different levels was used to design the experimental work for the preparation of Diacerein entrapped niosomes. These major factors include the percent of charge inducer $\left(\mathrm{X}_{1}\right)$, HLB values $\left(\mathrm{X}_{2}\right)$ and sonication time $\left(\mathrm{X}_{3}\right)$. So, fifteen formulae of different combinations were prepared, by taking values of the variables $\mathrm{X}_{1}, \mathrm{X}_{2}$ and $\mathrm{X}_{3}$ at different levels as shown in table (1).

Table (1): Diacerein entrapped niosomes formulation according Box-Behnken design

\begin{tabular}{|c|c|c|c|c|c|c|}
\hline \multirow[t]{3}{*}{ Formula No. } & \multicolumn{6}{|c|}{ Variable level in coded form } \\
\hline & \multicolumn{2}{|c|}{ X1 (charge inducer) } & \multicolumn{2}{|c|}{ X2 (HLB value) } & \multicolumn{2}{|c|}{ X3 (Sonication time) } \\
\hline & Actual & Coded & Actual & Coded & Actual & Coded \\
\hline Formula 1 & $5 \%$ & 0 & 14.9 & -1 & $5 \min$ & 1 \\
\hline Formula 2 & $0 \%$ & -1 & 15.25 & 0 & $5 \min$ & 1 \\
\hline Formula 3 & $5 \%$ & 0 & 15.6 & 1 & $5 \min$ & 1 \\
\hline Formula 4 & $0 \%$ & -1 & 15.25 & 0 & $0 \min$ & -1 \\
\hline Formula 5 & $0 \%$ & -1 & 15.6 & 1 & $2.5 \mathrm{~min}$ & 0 \\
\hline Formula 6 & $5 \%$ & 0 & 14.9 & -1 & $0 \min$ & -1 \\
\hline Formula 7 & $10 \%$ & 1 & 15.25 & 0 & $5 \mathrm{~min}$ & 1 \\
\hline Formula 8 & $10 \%$ & 1 & 15.25 & 0 & $0 \min$ & -1 \\
\hline Formula 9 & $10 \%$ & 1 & 15.6 & 1 & $2.5 \mathrm{~min}$ & 0 \\
\hline Formula 10 & $5 \%$ & 0 & 15.6 & 1 & $0 \mathrm{~min}$ & -1 \\
\hline Formula 11 & $0 \%$ & -1 & 14.9 & -1 & $2.5 \mathrm{~min}$ & 0 \\
\hline Formula 12 & $10 \%$ & 1 & 14.9 & -1 & $2.5 \mathrm{~min}$ & 0 \\
\hline Formula 13 & $5 \%$ & 0 & 15.25 & 0 & $2.5 \mathrm{~min}$ & 0 \\
\hline Formula 14 & $5 \%$ & 0 & 15.25 & 0 & $2.5 \mathrm{~min}$ & 0 \\
\hline Formula 15 & $5 \%$ & $\overline{0}$ & 15.25 & $\overline{0}$ & $2.5 \mathrm{~min}$ & 0 \\
\hline
\end{tabular}

\section{Characterization of Diacerein Niosomes}

\section{Photo microscopy}

Vesicle dispersions were characterized by photo microscopy for vesicle formation and morphology. Samples of Niosomal formulations were examined under optical microscope by means of fitted camera and photographed at magnification of 40 to $100 \mathrm{X}$ (Abdelbary and Elgendy, 2008).

\section{Determination of vesicle size}

This is performed for characterization of vesicle's size. Vesicle size of niosomes were determined by using Malvern Mastersizer (Abdelbary and Elgendy, 2008).

\section{Determination of Diacerein entrapment efficiency}

The prepared Diacerein niosomes were separated from unentrapped drug by centrifugation at $7000 \mathrm{rpm}$ for 30 minutes. The isolated layers were washed twice with PBS 7.4 and recentrifuged again (El-Ridy et al., 2008; Hu et al., 1999 and Silver et al., 1985). The amount of Diacerein entrapped was estimated indirectly by measuring the unentrapped 
drug in the washing and subtracting it from the total initial amount of Diacerein used at the start of the niosomes preparation.

\section{In vitro release of Diacerein from niosomes}

All niosomal formulae were employed in this examination. Each preparation was separated, washed and the amount of Diacerein entrapped was determined (as mentioned above).

The amount of drug retained at zero time was considered as the total amount of drug. The pellet of each preparation was then suspended using phosphate buffer solution (PBS) 7.4 to exactly $500 \mathrm{ml}$. The Rotary shaker was used to carry out the experiment. The device was adjusted to a rate of $80 \mathrm{stroke} / \mathrm{min}$ and the temperature was adjusted to $37-40^{\circ} \mathrm{C}$. A $5 \mathrm{ml}$ sample from each of the niosomal suspension was taken at different time interval. The samples were separated and filtered through $0.45 \mu \mathrm{m}$ filter, the amount of Diacerein released was determined at each time interval and the amount of Diacerein retained was then calculated at each time interval for each formula.

\section{Optimization of Diacerein niosomes:}

Statistical Correlation between Independent Variables (Charge inducer percent X1, HLB value X2 and Sonication time X3) and dependent response of Diacerein niosomes (Particle size Y1, Entrapment efficiency Y2 and In vitro release after 8 hrs Y3) using Statistical package STATGRAPHICS plus.

\section{Physical Stability of Diacerein Niosomes}

Physical stability of the prepared diacerein niosomes were carried out to investigate the leaching of down from niosomes (in a liquid form) during storage. The samples of niosomal formulations were sealed in a glass vial and stored at refrigeration temperature $(4 \mathrm{o}$ C), room temperature and elevated temperature $(40 \mathrm{oC})$ for a period of 2 months. Samples from each vial were withdrawn at definite time intervals, 15, 22, 30, $45 \& 60$ days, the residual amount of the drug in the vesicles was determined as described previously after separation from unentrapped drug (Singh et al., 2011).

\section{RESULTS AND DISCUSSION}

\section{Characterization of Diacerein Niosomes}

\section{Photo microscopy}

The photomicrograph of Diacerein niosomes prepared by thin film hydration method is shown in figure (1). They reveal that the niosomes were spherical in shape and exist in disperse and aggregate collections.
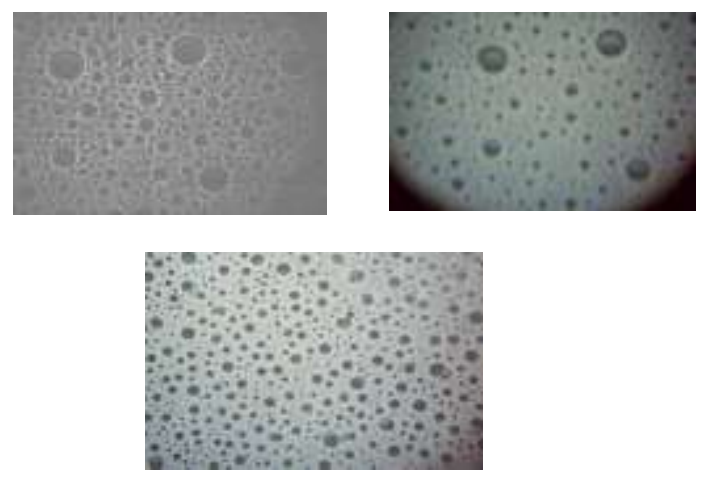

Figure (1): Photomicrograph of diacerein niosomes 


\section{Determination of vesicle size}

The means particle diameters of niosomes, composed of tween 40 and 60 with cholesterol are shown in table (2). The results reveal that formula 9(tween 40) has the smallest particle diameter $(7.33 \mathrm{um})$ while Formula 11(tween 60$)$ has the largest particle diameter (23.66 um).

\section{Determination of Entrapment efficiency:}

The entrapment efficiencies of all niosomal formulations composed of tween 40 and 60 with cholesterol are reported in Table (3). The results reveal that formula 11(tween 60) has the highest entrapment efficiency $(58.43 \%$ ) while Formula 15(tween 60\&40) has the smallest entrapment efficiency $(9.52 \%)$.

Table (2): Particle diameter of Diacerein Table (3): Entrapment efficiency of niosomes

\begin{tabular}{|l|l|}
\hline Formula & Particle size \\
\hline Formula 1 & $18.63 \mathrm{um}$ \\
\hline Formula 2 & $18.99 \mathrm{um}$ \\
\hline Formula 3 & $14.21 \mathrm{um}$ \\
\hline Formula 4 & $16.98 \mathrm{um}$ \\
\hline Formula 5 & $16.7 \mathrm{um}$ \\
\hline Formula 6 & $15.24 \mathrm{um}$ \\
\hline Formula 7 & $16.25 \mathrm{um}$ \\
\hline Formula 8 & $19.54 \mathrm{um}$ \\
\hline Formula 9 & $\mathbf{7 . 3 3} \mathbf{u m}$ \\
\hline Formula 10 & $12.72 \mathrm{um}$ \\
\hline Formula 11 & $\mathbf{2 3 . 6 6} \mathbf{u m}$ \\
\hline Formula 12 & $21.07 \mathrm{um}$ \\
\hline Formula 13 & $21.84 \mathrm{um}$ \\
\hline Formula 14 & $23.16 \mathrm{um}$ \\
\hline Formula 15 & $20.38 \mathrm{um}$ \\
\hline
\end{tabular}

\begin{tabular}{|l|l|}
\hline Formula & \% entrapped \\
\hline Formula 1 & 55.42 \\
\hline Formula 2 & 46.99 \\
\hline Formula 3 & 29.52 \\
\hline Formula 4 & 52.05 \\
\hline Formula 5 & 20.96 \\
\hline Formula 6 & 39.76 \\
\hline Formula 7 & 24.94 \\
\hline Formula 8 & 17.23 \\
\hline Formula 9 & 10.24 \\
\hline Formula 10 & 49.64 \\
\hline Formula 11 & $\mathbf{5 8 . 4 3}$ \\
\hline Formula 12 & 22.29 \\
\hline Formula 13 & 12.65 \\
\hline Formula 14 & 9.76 \\
\hline Formula 15 & $\mathbf{9 . 5 2}$ \\
\hline
\end{tabular}

\section{In vitro release of Diacerein from niosomes}

Results of an in vitro study on the release of diacerein niosomal vesicles prepared using Tween 40 and Tween 60 and mix of them are shown in Figs. 2, 3 and 4, respectively. The percentage of drug released after $8 \mathrm{~h}(\mathrm{Q} 8 \mathrm{~h})$ from the prepared niosomal vesicles are shown in Table (4). 


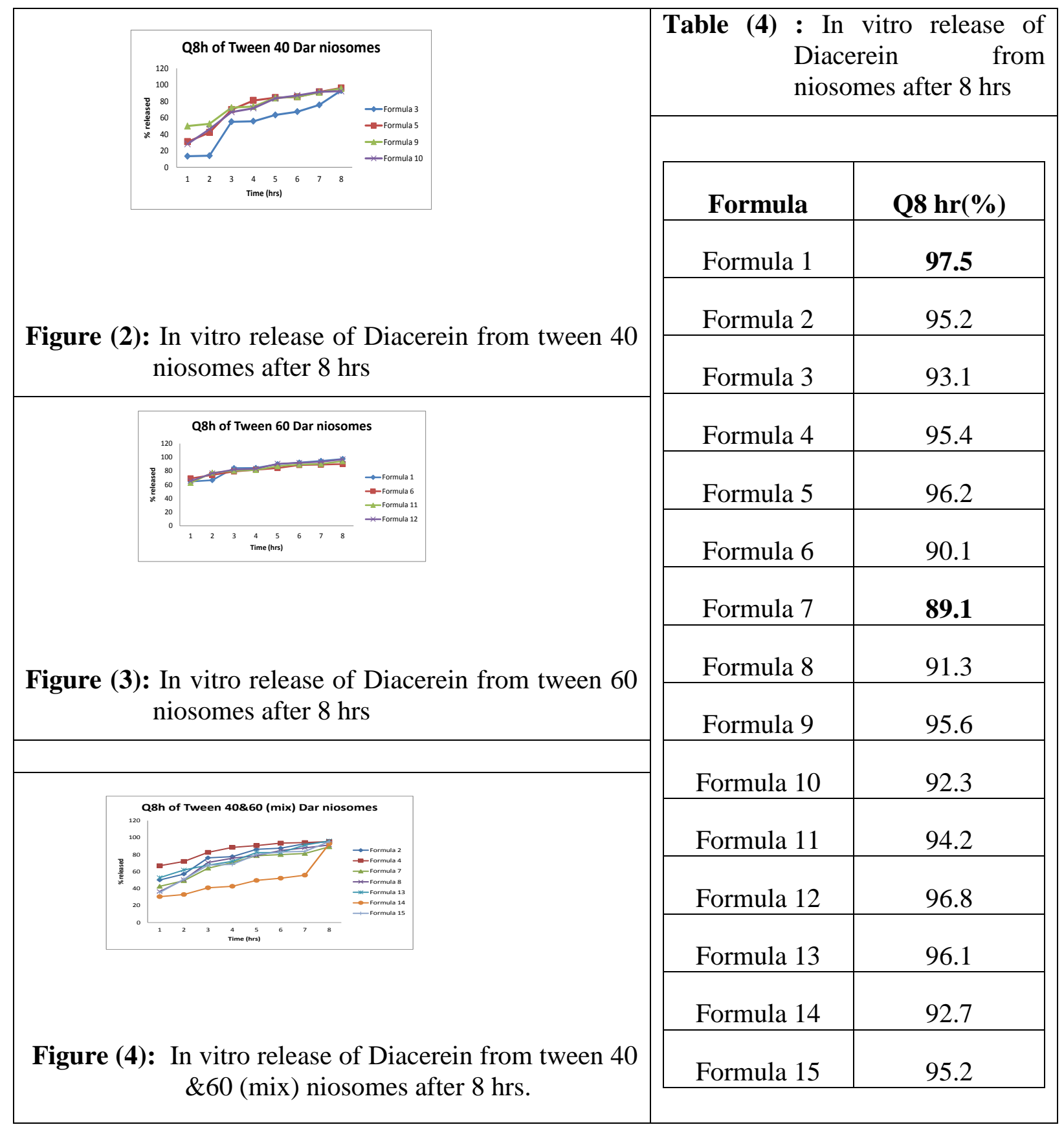

\section{Optimization:}

\section{Factorial Characterization of Diacerein niosomes}

The experimental runs and the observed responses for the Diacerein formulations are shown in table (5). The dependent variables studied were Y1 (particle size), Y2 (Entrapment efficiency) and Y3 (Release after $8 \mathrm{hrs)} \mathrm{based} \mathrm{on} \mathrm{the} \mathrm{experimental} \mathrm{design.} \mathrm{The} \mathrm{range} \mathrm{of} \mathrm{the}$ responses for Y1 was 23.66 um in F11 (maximum) and 7.33 um in F9 (minimum). While in $\mathrm{Y} 2$, the range of the responses was $58.43 \%$ in F11 (maximum) and $9.52 \%$ in F15 (minimum). The range of the responses for $\mathrm{Y} 3$ was $97.5 \%$ in $\mathrm{F} 1$ (maximum) and $89.1 \%$ in F7 (minimum).

The relationship between the dependent and independent variables was further elucidated using main effect plot. Figures (5-13) showed the effects of factors X1, X2 and X3 
on the response Y1, Y2 and Y3. The results given in these figures were manipulated in details as following:

Table (5): Full factorial design layout

\begin{tabular}{|c|c|c|c|c|c|c|}
\hline \multirow[t]{2}{*}{ Formula No. } & \multicolumn{3}{|c|}{$\begin{array}{l}\text { Variable level in } \\
\text { coded form }\end{array}$} & \multirow[b]{2}{*}{ Particle size (Y1) } & \multirow[b]{2}{*}{ E.E.(Y2) } & \multirow[b]{2}{*}{ Release (Y3) } \\
\hline & $\mathbf{X 1}$ & $\mathrm{X} 2$ & $\mathbf{X 3}$ & & & \\
\hline Formula 1 & 0 & -1 & 1 & $18.63 \mathrm{um}$ & 55.42 & 97.5 \\
\hline Formula 2 & -1 & 0 & 1 & 18.99 um & 46.99 & 95.2 \\
\hline Formula 3 & 0 & 1 & 1 & $14.21 \mathrm{um}$ & 29.52 & 93.1 \\
\hline Formula 4 & -1 & 0 & -1 & $16.98 \mathrm{um}$ & 52.05 & 95.4 \\
\hline Formula 5 & -1 & 1 & 0 & $16.7 \mathrm{um}$ & 20.96 & 96.2 \\
\hline Formula 6 & 0 & -1 & -1 & $15.24 \mathrm{um}$ & 39.76 & 90.1 \\
\hline Formula 7 & 1 & 0 & 1 & $16.25 \mathrm{um}$ & 24.94 & 89.1 \\
\hline Formula 8 & 1 & 0 & -1 & $19.54 \mathrm{um}$ & 17.23 & 91.3 \\
\hline Formula 9 & 1 & 1 & 0 & $7.33 \mathrm{um}$ & 10.24 & 95.6 \\
\hline Formula 10 & 0 & 1 & -1 & $12.72 \mathrm{um}$ & 49.64 & 92.3 \\
\hline Formula 11 & -1 & -1 & 0 & $23.66 \mathrm{um}$ & 58.43 & 94.2 \\
\hline Formula 12 & 1 & -1 & 0 & $21.07 \mathrm{um}$ & 22.29 & 96.8 \\
\hline Formula 13 & 0 & 0 & 0 & $21.84 \mathrm{um}$ & 12.65 & 96.1 \\
\hline Formula 14 & 0 & 0 & 0 & $23.16 \mathrm{um}$ & 9.76 & 92.7 \\
\hline Formula 15 & 0 & 0 & 0 & $20.38 \mathrm{um}$ & 9.52 & 95.2 \\
\hline
\end{tabular}

\section{Effect of X1, X2 and X3 on Y1 (particle size)}

Figure (5) standardized Pareto chart and figures (6-7) showed the main effects, interaction effects and quadratic effects of charge inducer (X1), HLB values (X2) and sonication time (X3) on the particle size. From the figures it was obvious that (X2) had the main effects on the particle size. Also it was noted that increasing X1 from $0 \%$ to $10 \%$ resulted in decreasing particle size from 22.5 um to 19.5 um (negative effect); increasing X2 from 14.9 to 15.6 resulted in increasing particle size from $21.6 \mathrm{um}$ to $22.78 \mathrm{um}$ then decreasing to $14.7 \mathrm{um}$ (negative effect); and increasing X3 from $0 \mathrm{~min}$ to $10 \mathrm{~min}$ resulted in increasing particle size from $18.4 \mathrm{um}$ to $21.8 \mathrm{um}$ then decreasing to $19.3 \mathrm{um}$ (positive effect).

Table (6) showed the ANOVA for the particle size. The statistical significance of each effect was tested by comparing the mean square against an estimate of the experimental error. In this case it was noted that the HLB value (X2) had p-value less than 0.05 indicating that it significantly different from zero at $95 \%$ confidence level. The R-squared statistic indicates that the model as fitted explains $80.75 \%$ of the variability in the particle size. The adjusted Rsquared statistic, which is more suitable for comparing models with different number of independent variables, is $46.12 \%$. The standard error of the estimate shows standard deviation of the residuals to be 3.167. The mean absolute error (MAE) of 1.516 is the average 
value of the residuals. The Durbin-Watson (DW) statistic tests the residuals to determine if there any significant correlation based on the order in which they occur in your data file. Since the DW value is greater than 1.4 (2.436), there is probably not any serious autocorrelation in the residuals.

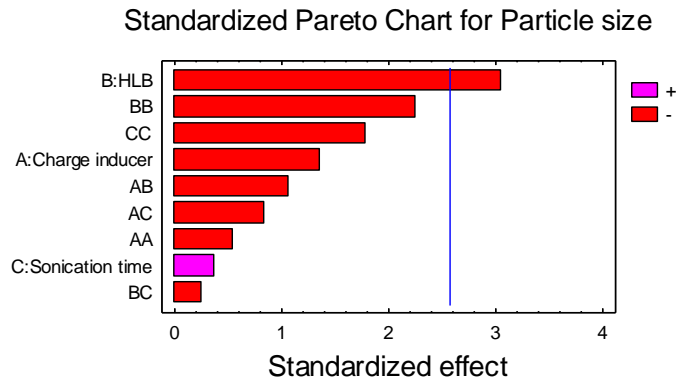

Figure (5): Standardized pareto chart showing the quadratic effect and interaction effect of $\mathrm{X} 1, \mathrm{X} 2$ and $\mathrm{X} 3$ on the particle size

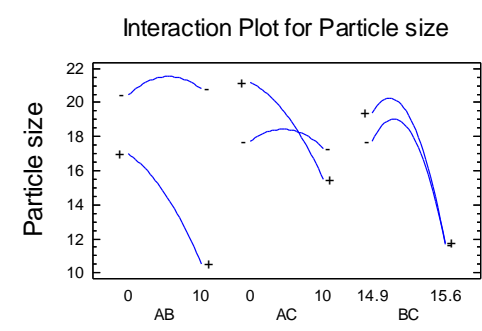

Table (6): Analysis of variance for Particle size

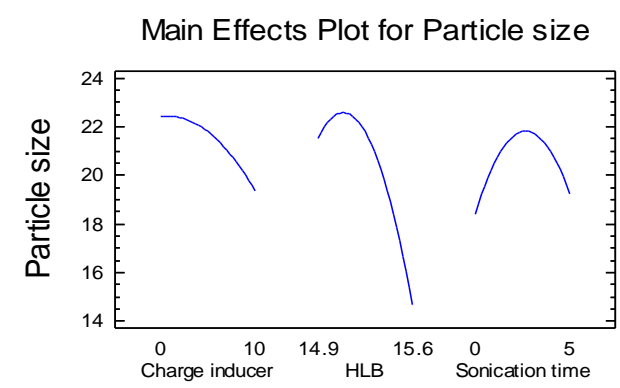

Figure (6): Main effect plot showing the effect of X1, X2 and X3 on the particle size

Figure (7): Main effect plot showing the interaction effect of X1, X2 and X3 on the particle size

\begin{tabular}{|l|l|l|l|l|l|}
\hline Source & sum of square & DF & Mean square & F-ratio & p-value \\
\hline A:Charge inducer & 18.4225 & 1 & 18.4225 & 1.84 & 0.2334 \\
\hline B: HLB value & 93.6396 & 1 & 93.6396 & 9.33 & 0.0283 \\
\hline C: Sonication time & 1.38611 & 1 & 1.3861 & 0.14 & 0.7253 \\
\hline AA & 2.97694 & 1 & 2.9769 & 0.30 & 0.6093 \\
\hline AB & 11.4921 & 1 & 11.4921 & 1.15 & 0.3334 \\
\hline AC & 7.0225 & 1 & 7.0225 & 0.70 & 0.4409 \\
\hline BB & 50.6958 & 1 & 50.6958 & 5.05 & 0.0745 \\
\hline BC & 0.664225 & 1 & 0.6642 & 0.07 & 0.8072 \\
\hline CC & 32.2504 & 1 & 32.2504 & 3.22 & 0.1329 \\
\hline Total error & 50.1551 & 5 & 10.0310 & & \\
\hline Total (corr.) & 260.63 & 14 & & & \\
\hline R-squrd & & & & & \\
\hline
\end{tabular}

R-squared $=80.7562$ percent

R-squared (adjusted for d.f.) $=46.1173$ percent

Standard Error of Est. $=3.16718$

Mean absolute error $=1.51644$

Durbin-Watson statistic $=2.43633(\mathrm{P}=0.1147)$ 


\section{Effect of X1, X2 and X3 on Y2 (entrapment efficiency)}

Figure (8) standardized Pareto chart and figures (9-10) showed the main effects, interaction effects and quadratic effects of charge inducer (X1), HLB values (X2) and sonication time (X3) on the entrapment efficiency. From the figures it was obvious that $(\mathrm{X} 3)^{2}$, $\mathrm{X} 1,(\mathrm{X} 2)^{2}, \mathrm{X} 2$ and $\mathrm{X} 2 \mathrm{X} 3$ respectively had the main effects on the entrapment efficiency. Also it was noted that increasing $\mathrm{X} 1$ from $0 \%$ to $10 \%$ resulted in decreasing entrapment efficiency from 28.2 to 2.2 (negative effect); increasing X2 from 14.9 to 15.6 decrease entrapment efficiency from 31.8 to 9.2 then increase to 15.8 (negative effect) and increasing X3 from 0 to 5 min resulted in decreasing entrapment efficiency from31.1 to 10.9 then increasing to 31 (no effect).

Table (7) showed the ANOVA for the entrapment efficiency. The statistical significance of each effect was tested by comparing the mean square against an estimate of the experimental error. In this case it was noted that 5 effects (the charge inducer X1, HLB value $(\mathrm{X} 2),(\mathrm{X} 2)^{2}$, sonication time $(\mathrm{X} 2 \mathrm{X} 3)$ and $\left.(\mathrm{X} 3)^{2}\right)$ had $\mathrm{p}$-value less than 0.05 indicating that it significantly different from zero at $95 \%$ confidence level.

The R-squared statistic indicates that the model as fitted explains $96.37 \%$ of the variability in the entrapment efficiency. The adjusted R-squared statistic, which is more suitable for comparing models with different number of independent variables, is $89.85 \%$. The standard error of the estimate shows standard deviation of the residuals to be 5.75 . The mean absolute error (MAE) of 2.83 is the average value of the residuals. The Durbin-Watson (DW) statistic tests the residuals to determine if there any significant correlation based on the order in which they occur in your data file. Since the DW value is less than 1.4 (1.2586), there is probably serious autocorrelation in the residuals.

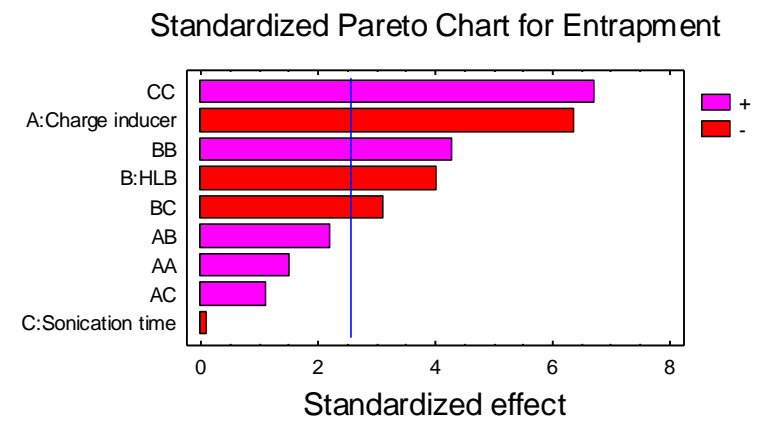

Figure (8): Standardized pareto chart showing the quadratic effect and interaction effect of particle size $\mathrm{X} 1, \mathrm{X} 2$ and $\mathrm{X} 3$ on the entrapment

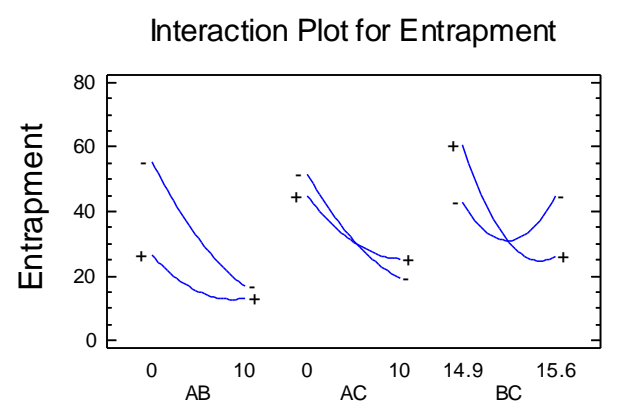

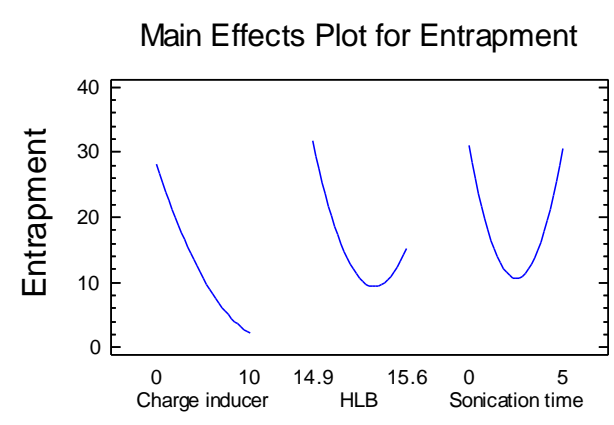

Figure (9): Main effect plot showing the effect of X1, X2 and X3 on the entrapment

Figure (10): Main effect plot showing the interaction effect of $\mathrm{X} 1, \mathrm{X} 2$ and $\mathrm{X} 3$ on the entrapment 
Table (7): Analysis of variance for Entrapement efficiency

\begin{tabular}{|c|c|c|c|c|c|}
\hline Source & sum of square & DF & Mean square & F-ratio & p-value \\
\hline A:charge inducer & 1344.9900 & 1 & 1344.9900 & 40.71 & 0.0014 \\
\hline B:HLB value & 536.9360 & 1 & 536.9360 & 16.25 & 0.0100 \\
\hline C:sonication time & 0.4095 & 1 & 0.4095 & 0.01 & 0.9157 \\
\hline AA & 75.6719 & 1 & 75.6719 & 2.29 & 0.1906 \\
\hline $\mathbf{A B}$ & 161.5440 & 1 & 161.5440 & 4.89 & 0.0780 \\
\hline $\mathbf{A C}$ & 40.7682 & 1 & 40.7682 & 1.23 & 0.3172 \\
\hline BB & 605.8540 & 1 & 605.8540 & 18.34 & 0.0078 \\
\hline BC & 320.0520 & 1 & 320.0520 & 9.69 & 0.0265 \\
\hline $\mathrm{CC}$ & 1496.5000 & 1 & 1496.5000 & 45.30 & 0.0011 \\
\hline Total error & 165.1940 & 5 & 33.0388 & & \\
\hline Total (corr.) & 4555.0400 & 14 & & & \\
\hline
\end{tabular}

R-squared $=96.3734$ percent

R-squared (adjusted for d.f.) $=89.8455$ percent

Standard Error of Est. $=5.74794$

Mean absolute error $=2.83456$

Durbin-Watson statistic $=1.25863(\mathrm{P}=0.0300)$

\section{Effect of X1, X2 and X3 on Y3 (release after 8 hours)}

Figure (11) the standardized pareto chart and figures (12-13) showed the main effects, interaction effects and quadratic effects of charge inducer (X1), HLB value (X2) and sonication time (X3) on the release after eight hours. From the figures it was obvious that no factor had effects on release after eight hours. Also it was noted that increasing X1 from $0 \%$ to $10 \%$ resulted in decreasing release after eight hours from $96 \%$ to 93.9 (negative effect); increasing X2 from 14.9 to 15.6 decrease release after eight hours from $95.6 \%$ to $94.6 \%$ then increasing to $95.4 \%$ (negative effect); and increasing X3 from 0 to 5 min resulted in increasing release after eight hours from $91.8 \%$ to $94.8 \%$ then decreasing to $93.2 \%$ (positive effect).

Table (8) showed the ANOVA for the release after eight hours. The statistical significance of each effect was tested by comparing the mean square against an estimate of the experimental error. In this case it was noted that none of the factors had p-value less than 0.05 indicating that it not significantly different from zero at $95 \%$ confidence level.The Rsquared statistic indicates that the model as fitted explains $54.89 \%$ of the variability in the release after 8 hours. The adjusted R-squared statistics, which are more suitable for comparing models with different number of independent variables, is $0 \%$. The standard error of the estimate shows standard deviation of the residuals to be 2.827 . The mean absolute error (MAE) of 1.428 is the average value of the residuals. The Durbin-Watson (DW) statistic tests the residuals to determine if there any significant correlation based on the order in which they occur in your data file. Since the DW value is greater than 1.4 (1.943), there is probably not any serious autocorrelation in the residuals. 
Standardized Pareto Chart for Release

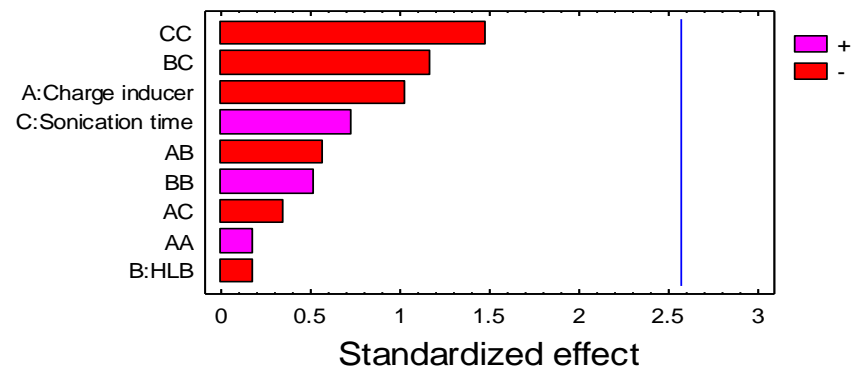

Figure (11): Standardized pareto chart showing the quadratic effect and interaction effect of $\mathrm{X} 1, \mathrm{X} 2$ and $\mathrm{X} 3$ on the release after 8 hours.

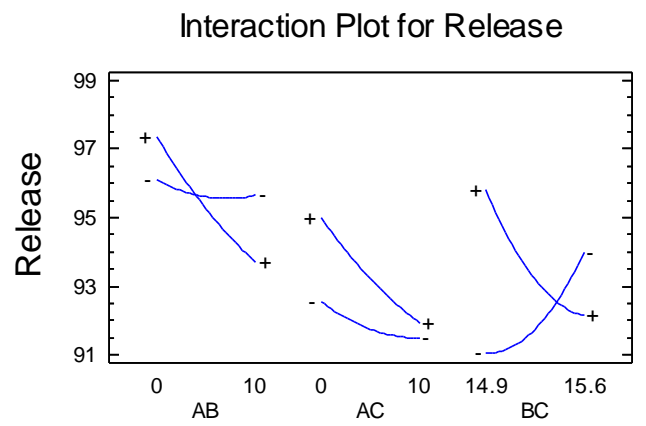

Main Effects Plot for Release

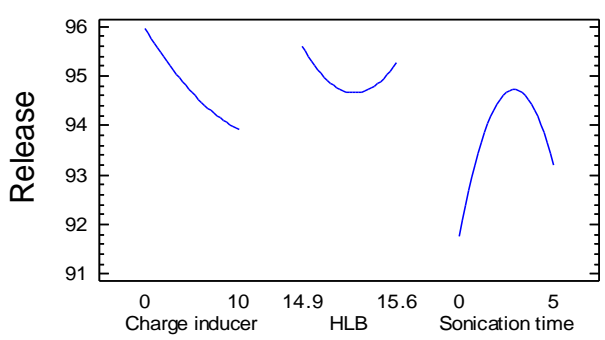

Figure (12): Main effect plot showing the effect of X1, X2 and X3 on the release after 8 hours.

Figure (13): Main effect plot showing the interaction effect of $\mathrm{X} 1, \mathrm{X} 2$ and $\mathrm{X} 3$ on the release after 8 hours

Table (8): Analysis of variance for Release after 8 hours

\begin{tabular}{|l|l|l|l|l|l|}
\hline Source & sum of square & DF & Mean square & F-ratio & p-value \\
\hline A: Charbe inducer & 8.405 & 1 & 8.4050 & 1.05 & 0.3523 \\
\hline B: HLB values & 0.245 & 1 & 0.2450 & 0.03 & 0.8679 \\
\hline C: Sonication time & 4.205 & 1 & 4.2050 & 0.53 & 0.5009 \\
\hline AA & 0.262564 & 1 & 0.2626 & 0.03 & 0.8633 \\
\hline AB & 2.56 & 1 & 2.5600 & 0.32 & 0.5960 \\
\hline AC & 1 & 1 & 1.0000 & 0.13 & 0.7380 \\
\hline BB & 2.17026 & 1 & 2.1703 & 0.27 & 0.6246 \\
\hline BC & 10.89 & 1 & 10.8900 & 1.36 & 0.2958 \\
\hline CC & 17.601 & 1 & 17.6010 & 2.20 & 0.1980 \\
\cline { 1 - 3 } Total error & 39.9817 & 5 & 7.9963 & & \\
\cline { 1 - 3 } Total (corr.) & 88.6373 & 14 & \multicolumn{2}{|l}{} &
\end{tabular}

R-squared $=54.893$ percent

R-squared (adjusted for d.f.) $=0.0$ percent

Standard Error of Est. $=2.82778$

Mean absolute error $=1.42889$

Durbin-Watson statistic $=1.94334(\mathrm{P}=0.3431)$

By applying the optimize response, the optimized formula containing Diacereinentrapped niosomes is obtained by using the independent variables as follow: Charge inducer (0 \%), HLB (15.6) and sonication time (0 min).Table (9) showed the observed and the predicted values of the responses for the optimized formula of Diacerein niosome that suggested by Factorial design. 
Table (9): Observed and predicted values of the responses for the optimized Diacerein niosomes

\begin{tabular}{|l|l|l|l|}
\hline Response & Observed & Predicted & Residual \\
\hline Particle size (Y1) & 14.8 & 12.8 & 2 \\
\hline Entrapment(Y2) & 60.5 & 58.43 & 2.07 \\
\hline Percent release after eight hours (Y3) & 97.8 & 95.58 & 2.22 \\
\hline
\end{tabular}

\section{Release Kinetics}

We determined the proper order of release of drug from different formulations by analyzing linear regression study. Zero, first and Higuchi diffusion controlled model equations were applied to all in vitro release results. From the results we can conclude that the drug was released from niosome by a zero, a first order and Higuchi diffusion controlled mechanism Table (10).

Table (10): The Calculated Correlation Coefficients for The In-Vitro Release of Diacerein Niosomes prepared by Box-Behnken design Employing Different Kinetic Orders or Systems

\begin{tabular}{|l|l|l|l|}
\hline Formula & Zero & First & Higuchi's \\
\hline F1 & 0.9413 & $\mathbf{- 0 . 9 8 0 7}$ & 0.96491 \\
\hline F2 & 0.9523 & $\mathbf{- 0 . 9 8 9 3}$ & 0.97799 \\
\hline F3 & 0.9456 & -0.9138 & $\mathbf{0 . 9 5 6 3 6}$ \\
\hline F4 & 0.9357 & $\mathbf{- 0 . 9 8 8 9}$ & 0.97021 \\
\hline F5 & 0.9240 & $\mathbf{- 0 . 9 7 8 3}$ & 0.96068 \\
\hline F6 & 0.9752 & -0.9914 & $\mathbf{0 . 9 9 3 4 5}$ \\
\hline F7 & 0.9635 & -0.9821 & $\mathbf{0 . 9 8 4 2 2}$ \\
\hline F8 & 0.9363 & $\mathbf{- 0 . 9 9 2 1}$ & 0.97255 \\
\hline F9 & 0.9660 & -0.9749 & $\mathbf{0 . 9 7 8 8 8}$ \\
\hline F10 & 0.9411 & $\mathbf{- 0 . 9 9 3 3}$ & 0.97676 \\
\hline F11 & 0.9339 & $\mathbf{- 0 . 9 7 9 7}$ & 0.96564 \\
\hline F12 & 0.9556 & -0.9816 & $\mathbf{0 . 9 8 2 9 8}$ \\
\hline F13 & $\mathbf{0 . 9 9 1 9}$ & -0.9474 & 0.99044 \\
\hline F14 & $\mathbf{0 . 8 8 1 0}$ & -0.7369 & 0.83798 \\
\hline F15 & 0.9581 & -0.9460 & $\mathbf{0 . 9 8 2 0 5}$ \\
\hline
\end{tabular}

\section{Physical Stability Study of Diacerein Niosomes}

Physical stability study of the prepared niosomes was carried out to investigate the leaching of drug from niosomes during storage at refrigerator condition, room temperature and elevated temperature. The percentage of Diacerein retained after a period of 7, 15, 22, 30, 45 \& 60 days in MLVs niosomes composed of tween 40 with cholesterol in molar ratio 1:1 are shown in table (11). Also the results indicate that maximum percentage drug retained was observed at refrigerated conditions than room temperature and elevated temperature, after 2 months study. This may be due to the higher fluidity of lipid bilayers at higher temperature resulting into higher drug leakage. 
Table (11): Physical stability study of Diacerein noisome

\begin{tabular}{|l|l|l|l|}
\hline \multirow{2}{*}{ Time } & \multicolumn{3}{|l|}{ Drug Retained } \\
\cline { 2 - 4 } & $\mathbf{4}^{\mathbf{}} \mathbf{C}$ & $\mathbf{2 5}^{\mathbf{}} \mathbf{C}$ & $\mathbf{4 0}^{\mathbf{}} \mathbf{C}$ \\
\hline 7 days & $60.5 \%$ & $60.7 \%$ & $60.5 \%$ \\
\hline 15 days & $60.2 \%$ & $60 \%$ & $59.5 \%$ \\
\hline 21 days & $60.2 \%$ & $59.8 \%$ & $58 \%$ \\
\hline 30 days & $60 \%$ & $59.7 \%$ & $55 \%$ \\
\hline 45 days & $59.8 \%$ & $59.2 \%$ & $48 \%$ \\
\hline 60 days & $59.7 \%$ & $59 \%$ & $45 \%$ \\
\hline
\end{tabular}

\section{CONCLUSION}

All this investigation conclusively demonstrate prolongation of drug release at a constant and controlled rate, after encapsulation of Diacerein. The study suggests that niosomal formulation can provide consistent and prolonged release of Diacerein from different niosomal formulations. It will lead to sustained action of the entrapped drug that reduce the side effects associated with frequent administration of the drug and potentiate the therapeutic effects of the drug.

It shows that niosomal drug delivery system may be a promising carrier for the novel drug delivery system.

\section{REFERENCES}

Abdul Hasan Sathali A., Rajalakshmi G., (2010): Evaluation of transdermal targeted niosomal drug delivery of Terbinafine hydrochloride, Int. J. of pharma tech research, vol 2, no 3, pp 2081-2089.

Azmin, M.N., Florence, A.T., Handjani-Vila, R.M., Stuart, J.F.B., Vanlerberghe, G., Whittaker, J.S., (1985): The effect of non-ionic surfactant vesicle (niosome) entrapment on the absorption and distribution of methotrexate in mice, J. Pharm. Pharmacol., 37, 237-242.

Biju, SS; Talegaonkar, S; Mishra, PR and Khar, RK, (2006): "Vesicular Systems: An Overview", Indian Journal of Pharmaceutical Sciences, 68(2), 141-153.

Box, G. E. P., and Behnken, D. W., (1960): Some new three level design for the study of quantitative variables, Technometrics, 2, 455-475

Chawda Himmat Singh, Jain CP, (2011): Bairwa Narendra Kumar: Formulation, Characterization, Stability and In-vitro evaluation of Nimesulide niosomes. Pharmacophore J.vol 2 (3), 168-185,

El-Ridy M.S., Abd El-Rahman A.A. and Kassem A.A., (2008): Study of niosomal encapsulation of the tuberculocidal drug rifampicin, Master thesis, Faculty of pharmacy, Cairo university, Egypt, 120-123.

Fidelix TS, Soares BG, Trevisani VF. Fidelix, Tania S.A. (2006): ed. "Diacerein for osteoarthritis". Cochrane database of systematic reviews (Online) (1): CD005117. doi:10.1002/14651858.CD005117.pub2. PMID 16437519. 
Ghada Abdelbary, Nashwa El-gendy, (2008): Niosome-encapsulated gentamicin for ophthalmic controlled delivery, AAPS PharmSci Tech, vol 9, no 3, pp 740-747.

Hu C. and Rhodes D.G., (1999): proniosomes: a novel drug carrier preparation, Int. J. of Pharm., 185, 23-35.

Sakthivel M1, Kannan K, Manavalan R, Senthamarai R (2012): Formulation and In-vitro evaluation of niosomes containing Oxcarpazepine International Journal of Pharmacy and Pharmaceutical Science Vol 4, Issue 3,563-567.

Satturwar, PM; Fulzele, SV; Nande, NS and Khandare, JN, (2002): "Formulation and evaluation of ketoconazole niosomes", Indian Journal of Pharmaceutical Sciences, Vol.64, 155-8.

Shahiwala, A and Misra, A, (2002): "Studies in topical application of niosomally entrapped nimesulide", J. Pharm. Sci., 5 (3), 220-225.

Sheena, IP; Singh, UV; Kamath, R; Umadevi, P and Udupa, N, (1998): "Niosomal withaferin with better antitumor efficacy", Indian Journal of Pharm. Sciences, 60 (1),45-48.

Silver B.L., (Ed), (1985): The physical chemistry of membranes, Alan \& Unwin and Soloman press, New York, USA, 209-230.

Vyas, SP and Khar, RK, (2004): "Targeted and Controlled Drug Delivery, Novel Carrier Systems", First Reprint, CBS Publishers \& Distributors, New Delhi, 39.

$$
\begin{aligned}
& \text { صياغة وتوصيف ودراسة الثبات والاتاحة المعملية للنيوزومات المحتوية علي الاياسيرين } \\
& \text { عبد الصبور أحمد حسن، أحمد ليلة، فتحي ابر اهيم عبد الله، خالد محمد الصاي، علاء الدين علي قاسم } \\
& \text { قسم الصيدلانيات و الصيدلة الصناعية، كلية الصيدلة بنين، جامعة الأزهر. }
\end{aligned}
$$

النيوزومات هي حويصلات تتكون من منشطات سطحية غير أيونية ويمكن الحصول عليها من هدرجة المنشطات السطحية

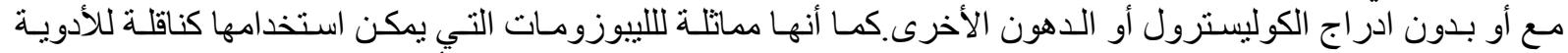

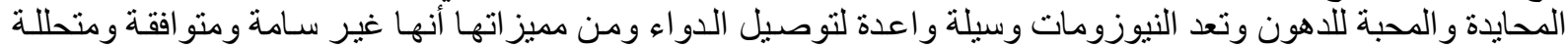

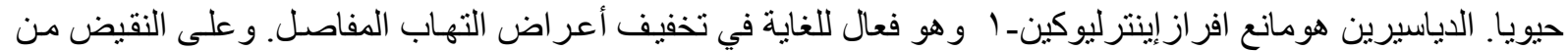

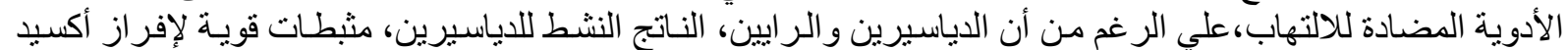

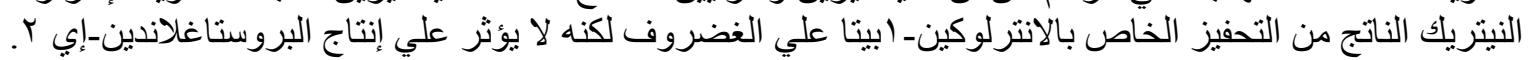

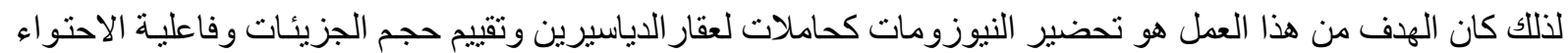

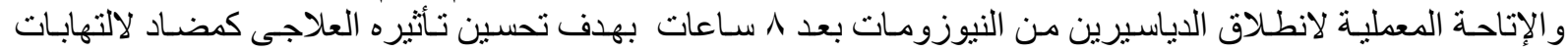
المفاصل.

وقد تم تحديد أقصى طول موجي لامتصاص وتثيييد المنحنيات المعياريـة للاياسيرين فى محلول منظم ذو أس هيدروجيني

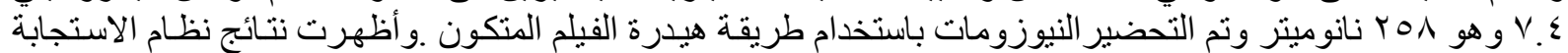

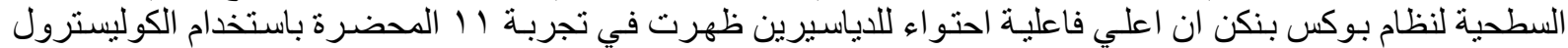

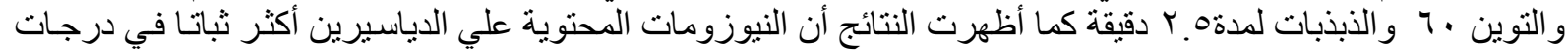

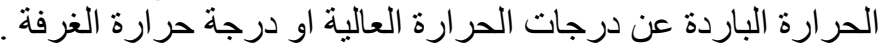

